\title{
Spatial Memory in Pigeons (Columba livia) in an Open-Field Feeding Environment
}

\author{
Marcia L. Spetch and Charles A. Edwards \\ Dalhousie University, Halifax, Nova Scotia, Canada
}

\begin{abstract}
Pigeons, unlike rats, do not display very accurate spatial working memory when tested in the traditional radial arm maze apparatus unless they are given special and extended training (cf. Roberts \& Van Veldhuizen, 1985). One possible reason for their apparent "unpreparedness" to display spatial memory abilities in radial arm mazes is that, in the wild, pigeons tend to feed in open-field environments. In these experiments, pigeons' spatial working memory abilities were tested in two multiple-goal open-field test environments. The first involved an open room with eight elevated food sites which the pigeons could fly to and eat from; the second involved an open room with ground-feeding sites, arranged in a circle or in rows, which the pigeons could walk to and eat from. Unlike the radial arm maze, these environments allowed the pigeon to choose its own path between food sites. Within only a few trials, pigeons displayed evidence of reasonably accurate spatial working memory in the flight apparatus and showed very high levels of accuracy in the ground-feeding apparatus. Thus, pigeons can display accurate spatial memory, but their "preparedness" to do so may be facilitated by the use of test environments that resemble the natural feeding habitats of the species. It is suggested that the ground-feeding apparatus developed here offers some unique advantages for studying the organization of spatial memory in pigeons.
\end{abstract}

The radial arm maze apparatus (Olton, 1977) has been used extensively over the past few years to study short-term, or "working," memory for spatial locations in animals. The basic radial maze task involves baiting the distal end of each arm with a piece of food and then placing the animal in the center of the maze and allowing it to choose among the arms until it locates all of the food. Because food is not replenished within a trial, the most efficient way to perform on this task is to visit each arm only once. Olton (1977) and numerous others have shown that rats perform extremely well on this task, and there is good evidence that they accomplish their high levels of accuracy with the use of working memory (for reviews see Olton, 1978; Roberts, 1984); that is, rats can remember which spatial locations they have already been to and avoid returning to them within the trial.

A few other animal species have also been found to display accurate spatial working memory. Wilkie and Slobin (1983) tested gerbils on a 17-arm radial maze and found excellent spatial memory performance. Ring doves have also been found to perform accurately after extensive training in a spatial memory task involving a variant of the radial maze in which the "arms" consisted of 14 short tubes, arranged in two levels, that radiated from a large center area (Wilkie, Spetch,

This research was supported by Natural Sciences and Engineering Reseach Council of Canada Operating Grant U0301 held by Marcia L. Spetch.

We are grateful to W. K. Honig. C. H. Jones. B. R. Moore, and D. R. Treit for their many valuable comments and suggestions. We also thank D. E. Armstrong. D. L. Davis. and S. H. Stewart for their assistance in conducting the research.

Correspondence concerning this article should be addressed to Marcia L. Spetch, Department of Psychology, Dalhousie University, Halifax, Nova Scotia, Canada B3H $4 \mathrm{JI}$.
\& Chew, 1981); the doves flew to perches attached to the entrance of each tube and then walked down the tube to obtain the food. Moore and Osadchuk (1982) reported that Savannah sparrows also performed accurately when tested outdoors in an 8-arm radial maze. Finally, field work and laboratory studies with seminatural environments have provided evidence for excellent spatial memory capacities in chimpanzees (Menzel, 1973, 1978), the amakihi, a nectarfeeding bird (Kamil, 1978), and a number of food-storing birds such as Clark's nutcrackers (Balda \& Turek, 1984; Tomback, 1980; Vander Wall, 1982), marsh tits (e.g., Cowie, Krebs, \& Sherry, 1981; Sherry, 1982), and black-capped chickadees (Sherry, 1984). In contrast, Betta splendens have been found to display only very moderate use of working memory in an aquatic radial arm maze (Roitblat, Tham, \& Golub, 1982).

Another species for which it has proven difficult to demonstrate the use of accurate working memory in the radial maze is the pigeon (Columba livia). Bond, Cook, and Lamb (1981) compared the performances of rats and pigeons on the same eight-arm radial maze and found lower accuracy in the pigeons. After performing a memory set analysis of their results, Bond et al. concluded that "at best, therefore, the birds were using only half the memory capacity of the rats; at worst, they might not have been using spatial memory at all" (p. 579). They speculated that the pigeons' poorer performance might reflect their evolutionary history: Because pigeons tend to feed from feeding grounds that are not easily depleted within a single feeding, they should have evolved a tendency to return to locations from which they have fed (a win-stay bias) and an accurate long-term memory for these locations. However, according to Bond et al., working memory for which particular locations they visited recently would not be selected for under these conditions. 
Although Bond et al.'s (1981) failure to find evidence for accurate spatial working memory in radial arm maze tasks with pigeons is consistent with other observations (Olson \& Maki, 1983; Wilkie \& Spetch, unpublished data, 1980), their speculation about the source of the inaccurate performance has not been supported by subsequent research. Olson and Maki tested pigeons in a T-maze and found evidence for a strong win-shift strategy and excellent working memory for the side of the T-maze last visited. Thus, pigeons' poor performance on the radial maze task does not appear to be due to an inherent tendency to return to recently visited food sites or to an inability to remember where they have been last.

A recent study (Roberts \& Van Veldhuizen, 1985) has now provided evidence that with special training conditions, pigeons can display accurate spatial memory in a radial arm maze. The specific training procedures used by Roberts and Van Veldhuizen involved a gradual increment, over successive phases, in the number of alleys to be remembered. After this special training, which involved approximately 190 trials, the pigeons were given free choices with all eight arms open and were found to perform with accuracy levels comparable to those typically found with rats. Furthermore, both choice pattern analysis and subsequent experimentation indicated that this accurate performance was not dependent on response strategies and appeared instead to reflect spatial working memory.

The results of Olson and Maki (1983), and the more recent findings of Roberts and Van Veldhuizen (1985), indicate that pigeons are capable of remembering recently visited spatial locations. The question remains, however, as to why they do not display evidence of this capacity in the standard radial arm maze task without special training. One possibility is that some feature of the radial arm maze apparatus inhibits pigeons from displaying their spatial memory abilities. Roberts and Van Veldhuizen, for cxample, noted that the radial maze mirrors the type of geometric patterns found in the tunnels and burrows of wild rats but that under natural conditions pigeons tend to search for food in open and relatively unconstrained spatial areas. Consequently, pigeons may be unprepared to deal with the labyrinthine structure of a radial arm maze. Bond et al. (1981) also mentioned that their pigeons tended to orient through the wire mesh toward unsearched arms while at the end of an adjacent arm. They suggested that the structure of the maze could have disrupted spatial memory in pigeons because it forced them to always return to the center area rather than allowing them to travel directly between goals.

In this regard, it should be noted that the apparatus used to demonstrate spatial memory in ring doves resembled an open-field type of environment much more than do standard radial arm mazes: The center area was very large and the "arms" were very short. Choices could be made by either flying directly between perches or flying to the center of the floor and then up to a perch. The Savannah sparrows, on the other hand, were tested in a more standard, structured radial arm maze. It is interesting, however, that the feeding habitats of Savannah sparrows include areas with an overhead cover of grass, and the birds' behavior in the wild has been described as having some rodentlike characteristics (e.g., Baird, 1968).
The present experiments were designed to test pigeons' spatial working memory in environments that were less constraining and perhaps more similar to pigeons' natural feeding habitats than is the radial arm maze. The first experiment employed a multiple-goal test environment that consisted of an open room with eight elevated "food sites" attached to three of the walls. The pigeons could choose among the sites by hopping or flying to perches which projected from each site. The second experiment employed a ground-feeding version of this multiple-goal apparatus in which eight food sites (milk cartons with a circular entrance hole cut on one side) were located on the floor of the open room. The pigeons chose among these ground-feeding sites by walking around and "entering" the cartons (i.e., inserting the head into the hole) to find food that was hidden inside each carton. The main feature of the flight and the ground-feeding open-field environments that differentiated them from the radial arm maze was the absence of constraints on choice paths: The pigeons were free to travel directly from one site to another, or they could return to the center of the room between choices.

\section{General Method}

\section{Subjects}

Four naive White Carneaux pigeons, between 6 months and 1 year of age, were used in Experiment 1. These same subjects (Birds 1-4) also served in Experiment 2, along with 6 additional White Carneaux pigeons (Birds 5-10). Bird 8 was under 1 year of age and was experimentally naive; the remaining subjects were between 1 and 3 years of age and had varied experimental histories in operant chambers. All subjects were maintained at $80 \%-85 \%$ of their free-feeding weights by grain obtained during and after experimental sessions. The birds were housed in individual wire mesh cages with water and grit freely available.

\section{Apparatus}

The open-field environment used in both experiments consisted of a rectangular test room $240 \times 230 \times 243 \mathrm{~cm}$, with two windows located on the inside wall (see Figure 1). One window was opaque, but the other window $(65 \mathrm{~cm}$ square and $98 \mathrm{~cm}$ from the floor) contained a one-way glass through which the test room could be viewed from an adjacent observation room. All walls of the test room and the inside of the door were painted white. However, a number of distinctive features were available to provide "spatial landmarks." These included the door, a black light switch, and a beige thermostat on the first wall, a black wall socket on the second wall, the two windows on the third wall, and a black wall socket and doorstop on the fourth wall. In addition, the overhead light (a 100-W light bulb that could be turned on and off from within the observation room) was located slightly closer to the third and fourth walls, with the electrical cord running to a small hole located near the ceiling on the third wall.

The locations of the eight elevated food sites ("perches") used in the first experiment are shown in Figure 1. The eight perches were all identical and were constructed of sheet metal and wire mesh. The base of each perch was $10 \times 15 \times 3 \mathrm{~cm}$ and was located $36 \mathrm{~cm}$ from the floor. The base was welded to a sheet-metal backing. $10 \times 30 \times$ $1 \mathrm{~cm}$, that was attached with screws to the wall. A circular hole, $5 \mathrm{~cm}$ in diameter, was cut in the base, $1 \mathrm{~cm}$ from the backing (edge to edge), to hold a food cup. Each food cup was painted white and was 


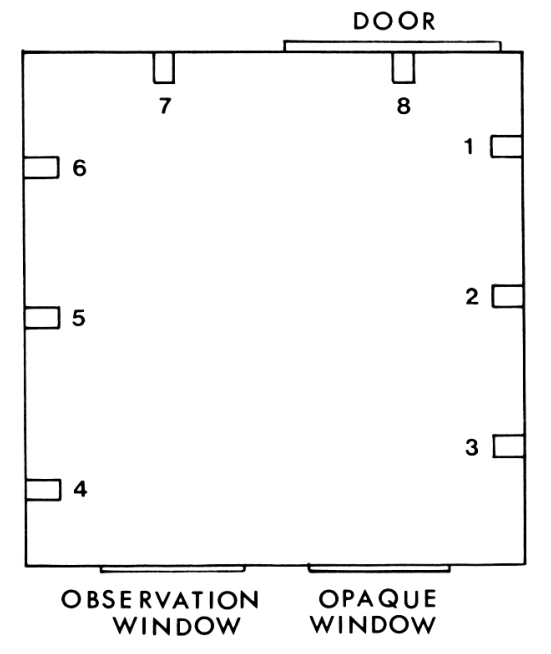

Figure 1. Top-view diagram of the test room and food-site ("perch") locations used in Experiment 1.

$8.5 \mathrm{~cm}$ deep so that food inside the cup could be seen only from the perch. Each perch also contained a sheet-metal "cover" that was hinged to the perch backing above the food cup. When lowered, the cover formed a $45^{\circ}$ angle that prevented the pigeon from landing on the perch or obtaining access to the food cup. Wires connected to each cover were fed through a pulley system across the ceiling to the observation room so that the covers could be raised without the experimenter's entering the test room.

The eight ground-feeding sites used in Experiment 2 consisted of 2-liter milk cartons with the tops cut off to provide light and with circular holes $(7 \mathrm{~cm}$ in diameter) cut on one side $16 \mathrm{~cm}$ from the bottom of the carton, edge to edge) to provide "entrances." Each 20 $\times 9.5 \times 9.5 \mathrm{~cm}$ carton contained a $3-\mathrm{cm}$ layer of grit. The food sites were baited by placing kernels of corn on the grit directly against the carton wall $3 \mathrm{~cm}$ below the entrance hole. In this way the food remained hidden from sight until the pigeon inserted its head at least part way into the food site. During most of Experiment 2, the eight food sites were all visually distinct. consisting of red, black, and bluc cartons with various patterns and markings. However, eight identical black cartons were used during some test phases. The cartons were placed on the foor in various spatial arrangements (described in Experiment 2).

\section{Procedure}

Pretraining. Each bird received one or more pretraining sessions that each lasted for $60 \mathrm{~min}$. During the first of these sessions, the bird was placed in the test room with grain located in and around the food sites. Once the bird was reliably eating grain from the food sites, it then received one or more 60-min sessions in which food was placed in the food sites only. The number of pretraining sessions required before the birds were reliably eating from all of the food sites is presented in the results of each experiment.

Baseline procedure. For both experiments, sessions consisted of a single trial per day. 5 or 6 days a week. At the beginning of a trial, each of the eight food sites was baited with one maple pea (Experiment 1) or with four kernels of corn (Experiment 2); then the overhead light was extinguished, and the pigeon was released onto the floor in the center of the room. Once the experimenter had arrived at the observation window (about $30 \mathrm{~s}$ ), the light was turned on, and the bird's choice behavior was recorded. The birds were always observed to be on the floor (generally in the center of the room) when the light was turned on to start the trial. The trial ended once the bird had visited all eight food sites or after $15 \mathrm{~min}$. The light was extinguished either immediately (Experiment 1 ) or $1 \mathrm{~min}$ after (Experiment 2) the end of the trial, and then the bird was removed from the room to end the session.

The specific procedures used during test sessions are described in the Method section of each experiment.

Analysis of choice accuracy. Choice of a food site was defined in terms of landing on a perch in Experiment 1 and entry of any part of the head into a carton in Experiment 2 . For both experiments, the primary measure of choice accuracy used was the number of different food sites visited during the first eight choices. An additional measure of accuracy was provided by the total number of choices made until all eight sites were visited. These accuracy scores were compared with chance-level expectations of accuracy derived from computer simulations (based on 10,000 runs, or "trials") of random sampling from eight sites (cf. Spetch \& Wilkie, 1980). Because birds often traveled directly between food sites in both of these test environments, the simulations were programmed so that return to a chosen site could occur only after another choice had been made. This resulted in a slightly higher estimate of chance-level performance $(70 \%$ correct in the first eight choices) than the standard estimates based on random sampling with (immediate) replacement (66\% correct; Olton, 1978; Spetch \& Wilkie, 1980) and therefore provided a more conservative comparison for actual performance.

Choice patterns. Patterns of choice responses were analyzed during the last 5 (Experiment 1) or 10 (Experiment 2) sessions of acquisition by assigning a score, ranging from -3 to +4 , to each choice (with Choices 2-8 only). A score of zero represented a choice of the site most recently visited (i.e., a direct repeat error). Positive scores represented choices of sites that lay in the bird's dominant choice direction. and negative scores represented choices of sites in the other direction.' The value of the score indicated the degree of separation between sites (according to the numerical assignments shown in Figures 1 and 5), with a score of 1 for adjacently numbered sites, a score of 2 for sites separated by one other site, and so on. The proportion of each type of choice was calculated for each bird, and then the contribution of these response patterns to choice accuracy waszexamined by conducting computer simulations that incorporated an individual bird's choice biases (cf. Bond et al., 1981; Roberts \& Van Veldhuizen, 1985). Each simulation was based on 5,000 runs and provided an estimate of (a) the expected number correct in the first eight choices and (b) the expected number of choices required to visit all eight food sites. Thus, each simulation provided an expected level of choice accuracy based on each bird's tendency to make particular choices, but the simulated values assumed no memory of past choices. The $t$ test for matched pairs was used to determine whether the birds' accuracies differcd significantly from the simulated values.

'Dominant choice directions were always determined by cxamination of choice order data rather than by observation of the birds' actual turning behavior. In the open-ficld test environments, the turning direction for a given choice was often impossible to evaluate: for example, in the flight apparatus a bird would sometimes hop or fly to the floor, walk around the room, orient to a perch, back away, and then fly across the room to another perch. Similarly, in the ground-feeding apparatus, birds sometimes walked to the center of the room, or to an area behind the cartons, changing "turning" directions several times before making their choice. 


\section{Experiment 1}

This experiment was designed to test pigeons' spatial working memory in the flight apparatus and involved three phases. The first phase consisted of acquisition of the spatial memory task, with each trial involving free choice among the eight perches. The second phase was designed to eliminate the possibility that simple response strategies were responsible for the accurate performance, and it involved forced choice of four randomly selected perches followed by free choice among all eight perches. In the third phase, the retention interval between the four forced choices and the free-choice component of the trial was varied.

\section{Method}

Phase 1: Acquisition. This phase involved a minimum of 25 trials with the baseline procedure described in General Method. On the 25th trial and each trial thereafter, the choice accuracies (percentage correct in the first eight choices) of each bird during the preceding 15 trials were examined in terms of a stability criterion (cf. Squires \& Fantino, 1971). Accuracy was considered stable if the means of the preceding three blocks of five sessions did not differ by more than $5 \%$ and if there was no upward or downward trend for these means. Acquisition was terminated once this stability criterion had been reached (Session 25 for Birds 3 and 4, Session 27 for Bird 2, and Session 28 for Bird 1 ).

Phase 2: Forcect-choice training. This phase involved 25 trials in which the first four choices were "forced." At the beginning of each trial, the eight food cups were baited, and then the perch covers were lowered over four randomly selected sites. The pigeon was permitted to choose until it visited each of the four open sites: then the overhead light was extinguished, and the perch covers on the four unvisited sites were raised by pulling on the attached wires from within the observation room. Ten seconds later, the light was turned back on, and the birds were given free choice of all eight food sites. The bird was often still sitting on the last-chosen perch when the lights were turned on: however, this was not counted as a choice. Accuracy was assessed in terms of percentage correct in the first four free choices as well as the number of choices required to find all four unvisited sites during the free-choice part of the trial. Chance-level accuracy was estimated by computer simulations of random sampling from eight options, four of which were already incorrect. As before, the simulations were programmed so that the same option could not be chosen twice in a row. Because the pigeons sometimes began the free-choice period while sitting on an incorrect (i.e., visited) site. the simulations were additionally programmed so that the first choice included only three incorrect options

Phase 3: Retention interval tests. This phase began immediately after Phase 2 and consisted of 30 trials. The procedure was the same as that used in Phase 2 except that a delay (light out) of 3,30 , or 300 $s$ followed the forced choices on each trial. Once this delay had expired, the perch covers were raised, and the light was turned on to begin the free-choice part of the trial. The order of the delays was randomly selected for each bird within the constraint that each delay occurred twice in each block of six trials. As in Phase 1, the four covered perches were randomly selected for each trial.

\section{Results and Discussion}

Training to fly to and eat from each of the eight food sites was accomplished in five sessions for Birds 1 and 2. Birds 3 and 4 were not flying to the perches by the end of the third session and therefore required additional pretraining sessions (five for Bird 4, seven for Bird 3) in which they were "shaped" to fly to the perches by placing boxes beneath the perches to form a sort of stairway. Grain was placed on the top of these boxes to entice the birds onto them and finally onto the perch itself.

Once the experiment proper had begun, birds occasionally failed to complete a trial. Data from these incomplete trials were not included in the analysis, and the trial was repeated on the next day.

Phase 1: Acquisition. Figure 2 shows the percentage correct in the first eight choices for individual birds. Each data point represents performance averaged over blocks of five sessions, with the exception of Session Block 6, which shows performance for the 2 birds that were given additional training (two sessions for Bird 1 and three sessions for Bird 2). The figure shows a general increase in the percentage of correct choices over the acquisition sessions and shows asymptotic levels that are above the computer estimate of chance performance (indicated by the dotted line).

A paired $t$ test indicated that the percentage of correct scores was significantly higher during the last five sessions than during the first five sessions, $t(3)=6.97, p<.01$; the number of choices required to visit all eight perches also declined significantly from a mean of 15.8 during the first five sessions to a mean of 12.1 during the last five sessions, $t(3)=3.277, p<.05$. During the last five sessions, the percentage of correct scores was significantly higher than the $70 \%$ chance level value, $t(3)=5.2, p<.05$, and the number of choices to visit the eight sites was significantly less than the chance level value of $19.15, t(3)=7.44, p<.01$. Thus, the pigeons performed reasonably accurately in this spatial memory task, without the gradual introduction of the eight choices
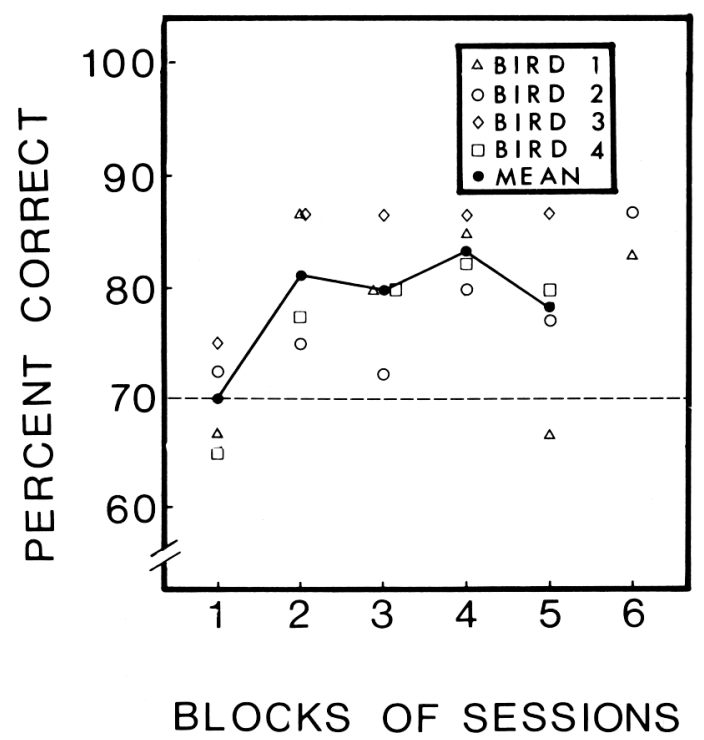

Figure 2. Percentage correct in the first eight choices during successive blocks of acquisition sessions in Phase 1 of Experiment 1 . 
that seems to be required in order for pigeons to perform well on the radial arm maze (Roberts \& Van Veldhuizen, 1985). However, the accuracy levels observed in this experiment were clearly not as high as those reported by Roberts and Van Veldhuizen for the pigeons that had been given the special training in the radial arm maze, or as high as those typically reported for rats in an eight-arm radial maze (e.g., Olton, 1978).

Table 1 shows the analysis of choice patterns for each bird during the last five trials as well as the birds' observed accuracy scores and the accuracy scores derived from computer simulations of sampling according to each bird's individual choice biases. The $t$ tests for matched pairs revealed that the birds were significantly more accurate in the first eight choices, $t(3)$ $=3.89, p<.05$, and took significantly fewer choices to visit all eight perches (obtained $M=12.1$, simulated $M=19$ ), $t(3)$ $=6.41, p<.01$, than predicted by the computer simulations based on choice biases and which assumed no memory for past choices. This suggests that the birds' choice biases alone were not sufficient to produce the obtained levels of accuracy on the spatial memory task.

Phase 2: Forced-choice procedure. The birds' percentage correct scores for the first four free choices are shown for successive blocks of five trials in Figure 3. By the last block of Phase 2, the birds' percentage correct scores $(M=68.8 \%)$ were significantly higher than the $45.5 \%$ computer estimate of chance-level accuracy (dashed line), $t(3)=6.2, p<.01$. In fact, this level of accuracy was not significantly different, $t(3)$ $=.293, p>.1$, from that obtained on the four choices that followed four correct free choices during the last block of Phase 1 ( $M=70 \%$ correct). By the last block of Phase 2, the mean number of choices (7.8) required to locate all four baited sites following forced choice was also significantly lower than the value of 14.7 estimated by computer simulations, $t(3)=7.6, p<.01$. These results provide further evidence against the possibility that the pigeons were avoiding previously visited sites on the basis of response strategies alone.

Phase 3: Retention tests. The birds' percentage correct scores declined slightly as a function of the retention interval as shown in Figure 4. A one-way analysis of variance revealed that the effect was significant, $F(2,6)=5.964, p<.05$. This small detrimental effect of the retention interval on choice accuracy is consistent with the results of Roberts and Van Veldhuizen (1985) for pigeons in an eight-arm radial maze. The mean number of choices required to visit all four correct

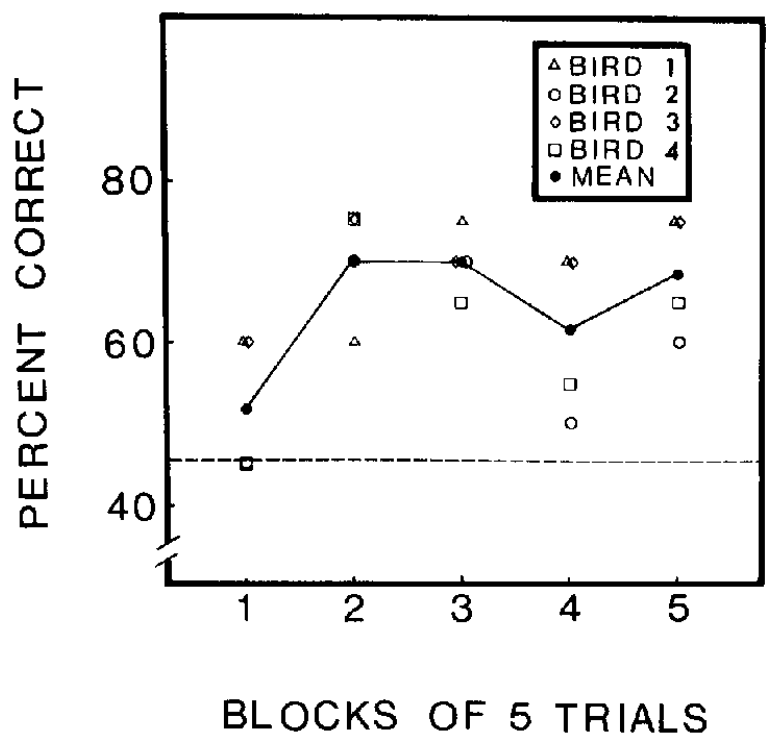

Figure 3. Percentage correct in the first four "free" choices for successive blocks of five trials with the forced-choice procedure in Phase 2 of Experiment 1.

sites increased slightly with increases in the retention interval $(M=6.7,7.2$, and 7.7 for $3-\mathrm{s}, 30-\mathrm{s}$, and 300 -s intervals, respectively), but these differences were not significant, $F(2$, $6)=1.02$.

\section{Experiment 2}

Pigeons performed reasonably accurately in the eight-goal flight apparatus of Experiment 1 without special or extended training, and they appeared to use memory for previously visited sites to guide choice behavior. Nevertheless, the apparatus did not seem to provide the ideal conditions for assessing pigeons' spatial memory abilities, because the birds were often very slow to make their choices. They frequently made only a few choices and then paused on a perch for several minutes before continuing with the trial. This problem became worse with continued testing and was not alleviated by increasing deprivation levels (subsequent to the last phase of Experiment 1). We encountered this problem again in another group of older pigeons that were subsequently trained on the flight apparatus. As this pausing behavior would result in the birds'

Table 1

Proportion of Choices of Food Sites at Different Units of Separation in the Preferred $(+)$ or Nonpreferred (-) Direction, and Observed and Simulated Accuracy for the Last Five Sessions of Phase la in Experiment 1

\begin{tabular}{|c|c|c|c|c|c|c|c|c|c|c|c|c|}
\hline \multirow[b]{2}{*}{ Subiect } & \multicolumn{8}{|c|}{ Choice proportion } & \multicolumn{2}{|c|}{$\begin{array}{l}\text { No. correct in first eight } \\
\text { choices }\end{array}$} & \multicolumn{2}{|c|}{$\begin{array}{l}\text { Total no. choices to } \\
\text { visit all eight sites }\end{array}$} \\
\hline & -3 & -2 & -1 & 0 & +1 & +2 & +3 & +4 & Observed & Simulated & Observed & Simulated \\
\hline $\begin{array}{l}1 \\
2 \\
3 \\
4\end{array}$ & $\begin{array}{l}.029 \\
.086 \\
0 \\
.028\end{array}$ & $\begin{array}{l}.057 \\
0 \\
.028 \\
0\end{array}$ & $\begin{array}{l}.257 \\
.171 \\
.286 \\
.229\end{array}$ & $\begin{array}{l}0 \\
0 \\
0 \\
0\end{array}$ & $\begin{array}{l}.286 \\
.343 \\
.486 \\
.286\end{array}$ & $\begin{array}{l}.143 \\
.143 \\
.143 \\
.314\end{array}$ & $\begin{array}{l}.171 \\
.200 \\
.029 \\
.029\end{array}$ & $\begin{array}{l}.057 \\
.057 \\
.028 \\
.114\end{array}$ & $\begin{array}{l}6.2 \\
6.4 \\
7.0 \\
6.4\end{array}$ & $\begin{array}{l}5.58 \\
5.66 \\
5.34 \\
5.69\end{array}$ & $\begin{array}{r}14.4 \\
12.4 \\
9.8 \\
11.6\end{array}$ & $\begin{array}{l}19.29 \\
18.54 \\
19.82 \\
18.54\end{array}$ \\
\hline$M$ & .036 & .021 & .236 & 0 & .350 & .186 & .107 & .064 & & & & \\
\hline
\end{tabular}




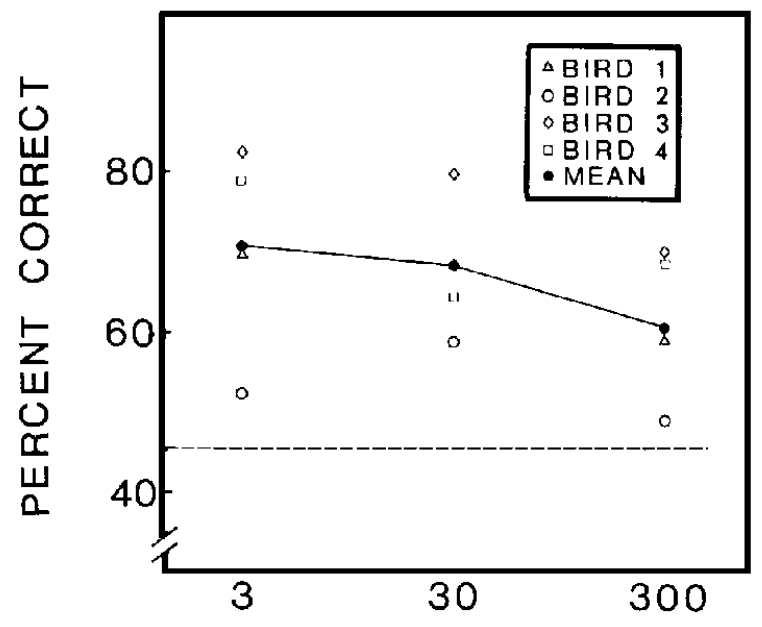

\section{RETENTION INTERVAL (SEC)}

Figure 4. Percentage correct during the first four "free" choices as a function of the retention interval between the forced-choice and free-choice parts of the trial during Phase 3 of Experiment 1. (Each data point is the average of 10 trials.)

imposing their own retention interval between choices, it seemed likely that the pigeons were not performing to the limits of their spatial memory capacity. On the assumption that the pausing problem might be reduced or eliminated by removing the flight requirement from the task, Experiment 2 was designed to test the pigeons' spatial working memory in a ground-feeding version of the open-field environment (a sort of "walking memory" task), in which the perches were replaced with food sites placed on the floor of the open room.

A second reason for developing the ground-feeding spatial memory apparatus was that it seemed to offer more flexibility for studying pigeons' spatial working memory as a function of the spatial organization of the food sites. Studies with rats have shown that the structure of mazes can have dramatic effects on accuracy levels and response strategies (e.g., Horner, 1984). Thus, in addition to providing a general test of pigeons' working memory abilities in an open-room ground-feeding environment, the present study also provided a preliminary examination of the effect of different spatial arrangements on pigeons' choice behavior.

Another question of interest addressed by the present study was whether pigeons would use differential visual cues associated with the food sites themselves to remember which sites they had already visited. The pigeons were therefore trained with visually distinct food sites and then tested with visually identical food sites placed in the same spatial locations used during training. This manipulation might be viewed as analogous to training with intramaze as well as extramaze cues and then testing with extramaze cues only. Although extramaze cues appear to dominate rats' memory in radial arm mazes, rats have been shown to use intramaze cues under certain conditions (e.g., Kraemer, Gilbert, \& Innis, 1983), and the results of some tests conducted by Roberts and Van
Veldhuizen (1985) suggested that their pigeons used both intramaze and extramaze cues to identify previously visited alleys in the radial maze.

\section{Method}

The pretraining and baseline procedures described in General Method were used for all phases of this experiment.

Phase 1a: Circular arrangement, visually distinct food sites. During this first phase, eight visually distinct food sites were arranged in a circle, with the entrance of each carton facing toward the center of the room, as shown in the left panel of Figure 5. The cartons were spaced approximately $45 \mathrm{~cm}$ apart, edge to edge, except for cartons 1 and 8 which were separated by about $90 \mathrm{~cm}$. The 4 "experienced" pigeons from Experiment 1 were tested for 10 trials; the remaining 6 subjects, for which both the apparatus and the procedure were novel, were tested for 25 trials.

Phase Ib: Circular arrangement, visually identical food sites. This phase consisted of two test trials (for all birds) in which eight visually identical food sites (black cartons) were placed in the same circular arrangement used in Phase la.

Phase 2a: Linear rous arrangement, visually distinct food sites. During this phase the eight visually distinct food sites were arranged in two rows of four sites each, with the entrances facing inward. Within a row, the cartons were spaced $20-22 \mathrm{~cm}$ apart. The distance between the rows differed between subjects. Half of the subjects (Birds 1, 2, 5, 6, and 7) were tested with the rows spaced 160 $\mathrm{cm}$ apart (the "far" arrangement shown in the middle panel of Figure 5). The remaining subjects were tested with rows spaced $40 \mathrm{~cm}$ apart (the "near" arrangement in the right panel of Figure 5). All subjects were tested for 10 trials under this condition.

Phase $2 b$ : Linear rows arrangement, visually identical food sites. For each bird, the eight visually identical black food sitcs were arranged in the same spatial arrangement used in Phase 2a. All subjects were tested for two trials.

Control trials. In order to ensure that the pigeons could not see or smell the food within the food sites before "entering" the carton (i.e., inserting any part of the head into the entrance), each bird received two control trials in which only four randomly selected food sites were baited. Behavior on these control trials was scored as for the baseline trials, and then entrances into the baited and unbaited sites were compared.

\section{Results and Discussion}

Pretraining to eat from the ground-feeding sites for Birds $1,2,3$, and 4 began approximately 4 months after their last tests in the flight apparatus of Experiment 1, and after a series of pilot experiments for the development of a ground-feeding apparatus. These birds were therefore exposed to different numbers and types of "food sites" during their preliminary training. Once the milk carton food sites had been established, these animals were trained within two sessions. Birds 5-10 were trained only with the milk carton food sites and were given a total of $4,3,6,5,7$, and 6 pretraining sessions, respectively.

Phase 1: Circular arrangement. The percentage correct in the first eight choices during Phase la (acquisition with visually distinct food sites) and during Phase $1 \mathrm{~b}$ (the test with visually identical sites) is shown in Figure 6 for the 4 experienced birds from Experiment 1 and for the 6 new birds. As 
CIRCULAR ARRANGEMENT

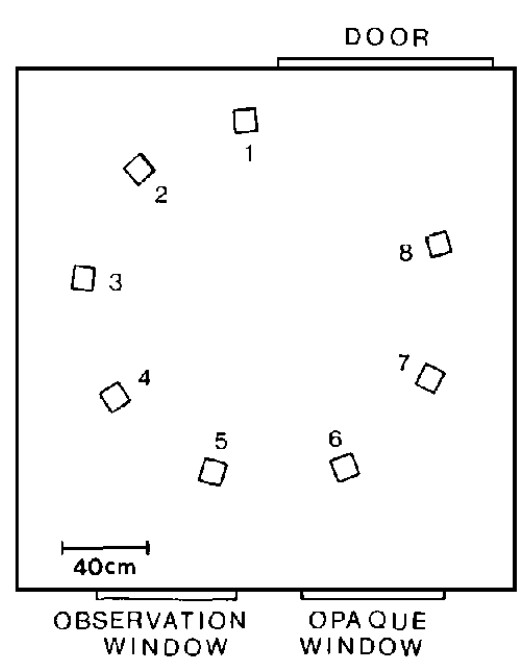

LINEAR "FAR" ARRANGEMENT

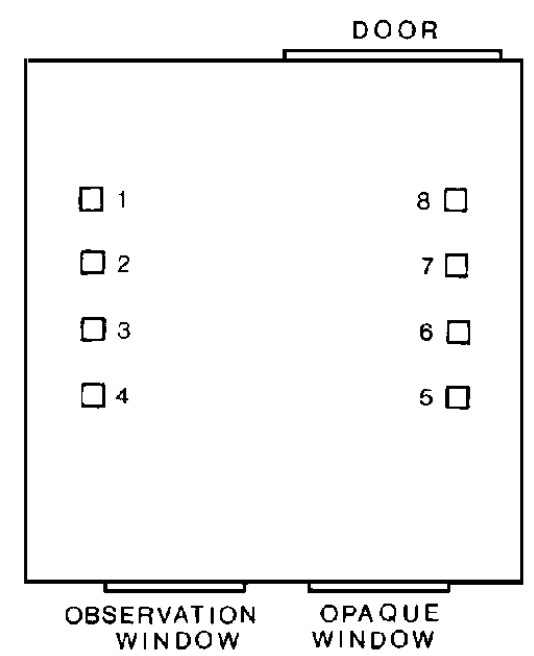

LINEAR "NEAR" ARRANGEMENT

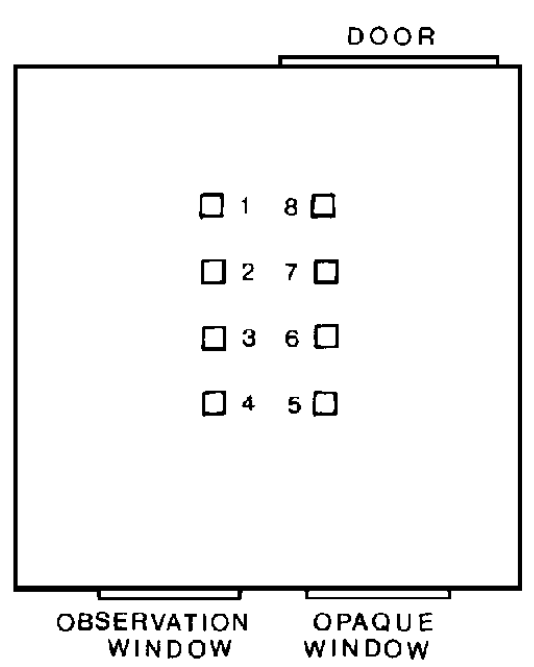

Figure 5. Top-view diagram of the three spatial arrangements of the ground-feeding sites used in Experiment 2.

can be seen, accuracy scores were very high from the outset for both groups of birds. Even during the first block of five trials in Phase 1a, accuracy scores were significantly above the $70 \%$ chance level for both the experienced birds $(M=$ $84.4), t(3)=5.2, p<.05$, and the new birds $(M=82.9), t(5)$ $=4.31, p<.01$. An analysis of variance on the accuracy data from both blocks of trials for the experienced birds and from the first two blocks of trials for the new birds revealed no significant difference between the two groups, $F(1,8)=0.678$, $p>.1$, and no significant interaction between groups and blocks of trials, $F(1,8)=0.084, p>.1$. The effect of blocks also failed to reach significance, $F(1,8)=3.77, p>.05$.

Several of the birds developed a fairly strong bias toward choosing adjacent food sites by the end of Phase 1a, whereas others showed very little consistency in response pattern (see Table 2). The left half of Figure 7 shows the choice patterns displayed during the last five trials by the bird from each group (i.e., ncw and experienced) that showed the least "circling" tendency. The right half of this figure shows choice patterns of the bird from each group that showed the greatest tendency to "circle" the maze. The behavior of Birds 2 and 9 clearly suggests the use of working memory, as the high levels of accuracy were achieved without the use of any consistent pattern of responding. In contrast, the behavior of Birds 4 and 8 suggests the use of a response strategy. Nevertheless, observation of behavior during the $1 \mathrm{~min}$ that followed the eighth choicc provided some indication that even the behavior of Bird 8 may have been controlled in part by working memory: On the five trials shown in the figure, this bird was never observed to continue its circling pattern after the eighth choice. On Trial 21, the bird turned back and approached (but did not enter) site 7, on Trials 22 and 24 it stopped and made no further choices, on Trial 23 it entered site 1 for its ninth choice, and on Trial 25 its ninth choice was site 3 .

All birds performed better during the last 10 trials of Phase la than expected from computer simulations based on their individual choice biases during these trials (Table 3). The number correct during the first eight choices was significantly higher than the simulated values for both the experienced birds (observed $M=7.0$, simulated $M=5.9$ ), $t(3)=4.05, p$ $<.05$, and the new birds (observed $M=7.3$, simulated $M=$ $6.0), t(5)=3.99, p<.05$. The birds' number of choices to visit all eight sites was also lower than the simulated values for the experienced birds (observed $M=10.2$, simulated $M$ $=16.8), t(3)=3.96, p<.05$, and the new birds (observed $M$ $=10.1$, simulated $M=16.2), t(5)=3.3, p<.05^{2}$

Percentage correct scores for the experienced birds were not significantly different during the two test trials with visually identical food sites in Phase $1 \mathrm{~b}(M=93.8)$ than they were during the preceding two trials in Phase la $(M=90.6), t(3)$ $=0.77$, and the mean percentage correct scores during the two conditions were identical $(89.6 \%)$ for the new birds. Similarly, there were no significant differences between the last two Phase la trials and the two Phase $1 \mathrm{~b}$ trials in terms of number of choices to visit all eight sites [experienced birds: Phase 1a $M=10$, Phase 1b $M=9.4, t(3)=0.66$; new birds: Phase la $M=9.7$, Phase lb $M=9.3, t(5)=0.80$ ]. The excellent performance observed with visually identical food sites suggests that the birds did not rely on visual cues associated with the cartons themselves to remember which food sites they had already visited.

Phase 2: Linear rows arrangement. Performance during Phases $2 \mathrm{a}$ and $2 \mathrm{~b}$ is shown in blocks of two trials for the 5 birds tested with the "far" rows in the left panel of Figure 8

\footnotetext{
${ }^{2}$ Some birds (e.g., Bird 6) showed a fairly strong tendency to choose an adjacent arm but also frequently reversed directions and thus produced a high proportion of +1 and -1 choices. Simulations based on these proportions tended to yield very low accuracy levels. This results because a strong tendency to choose either the left or the right adjacent site, coupled with no memory for which sites had already been chosen, would produce many incorrect choices.
} 

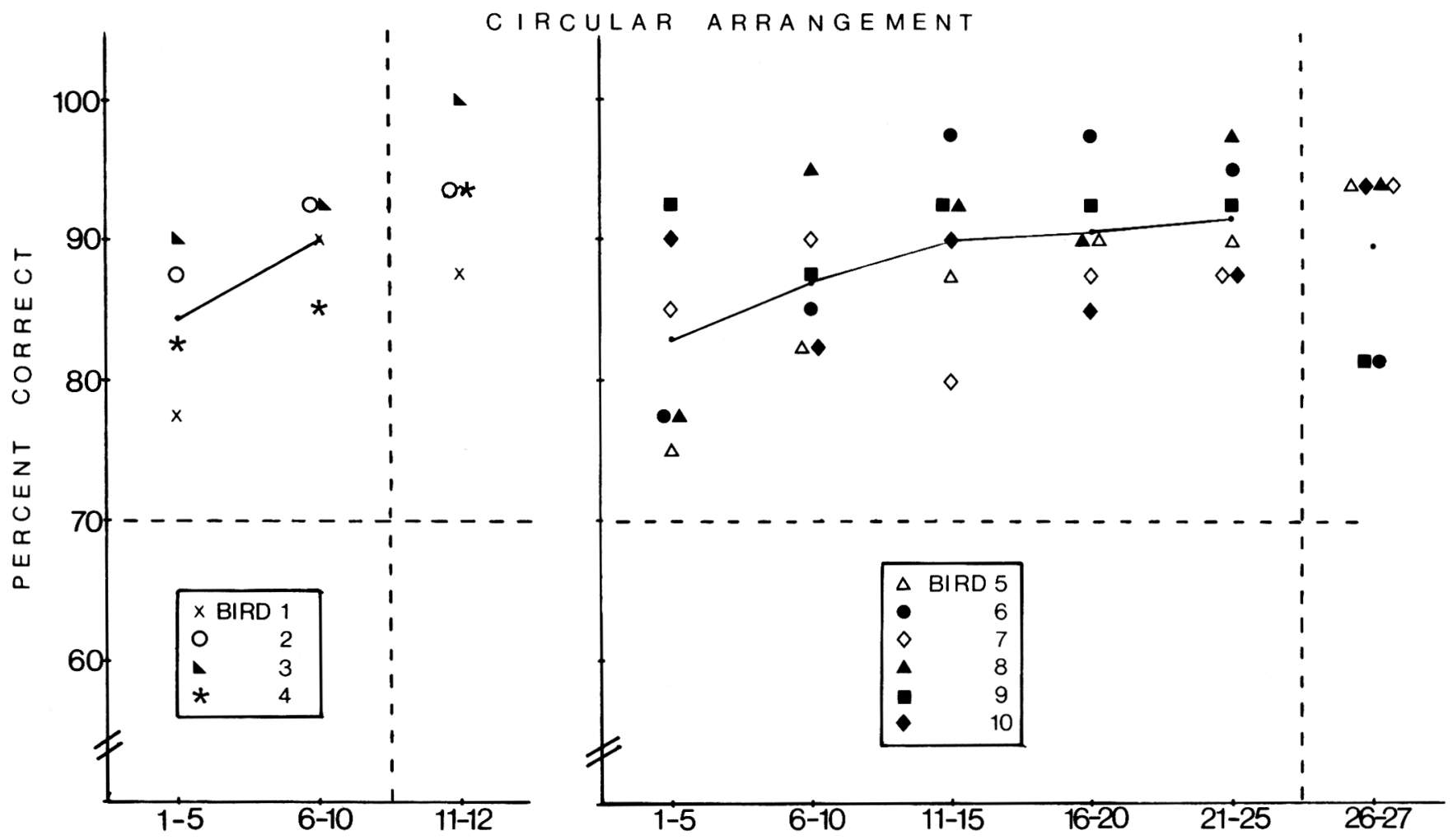

TR I A L S

Figure 6. Percentage correct in the first eight choices for the 4 experienced pigeons (left panel) and the 6 new pigeons (right panel) during successive blocks of trials with the circular arrangement in Experiment 2. (The points to the right of the vertical dotted lines are from the two test trials with visually identical food sites.)

and for the 5 birds tested with the "near" rows in the right panel of Figure 8 . During Phase $2 \mathrm{a}$, the accuracy scores of birds tested with the far arrangement were slightly higher than those tested with the near arrangement, although both groups performed well above chance level. A two-way analysis of variance on the accuracy scores for Phase 2 , with spatial arrangement as the between groups factor and trial blocks as the within factor, revealed a significant main effect of spatial arrangement, $F(1,8)=6.19, p<.05$, but not of blocks, $F(4$, $32)=1.64$, and no significant interaction, $F(4,32)=0.097$. A similar analysis on number of choices to visit all sites revealed a small but reliable effect of spatial arrangement (far group, $M=10.4$; near group, $M=11.0), F(1,8)=7.03, p<$ .05 , and no other significant effects.

Figure 9 shows the pattern of choices during the last five trials of Phase $2 \mathrm{a}$ for the birds previously observed to have low or high circling tendencies in the circular arrangement. It is interesting that the birds that had adopted a circling strategy in the circular arrangement did not continue to display a simple response pattern in the linear arrangement, and yet they were still able to achieve reasonably high levels of accuracy.

Comparisons of the birds' peformance with computer simulations based on response patterns (see Tables 2 and 3) revealed that both groups of birds visited significantly more food sites during their first eight choices [far group: observed $M=7.1$, simulated $M=5.9, t(4)=4.43, p<.05$; near group: observed $M=6.7$, simulated $M=5.6, t(4)=7.95, p<.01]$ and took significantly fewer choices to visit all sites [far group: observed $M=10.2$, simulated $M=16.7, t(4)=5.08, p<.01$; near group: observed $M=11.1$, simulated $M=18.8, t(4)=$ $9.56, p<.02]$ than expected on the basis of computer simulations.

The far group showed a significant decrement in percentage of correct scores during the test trials with visually identical cartons in Phase $2 \mathrm{~b}(M=82.5 \%)$ relative to the last two trials of Phase $2 \mathrm{a}(M=93.8 \%), l(4)=3.08, p<.05$. The mean percentage correct for the near group was not significantly different during Phase $2 \mathrm{~b}(86.2 \%)$ than during the preceding two trials of Phase $2 a(87.5 \%), t(4)=0.41$. For the far group, the number of choices to visit all sites was also somewhat higher during Phase $2 \mathrm{~b}(M=10.9)$ than during the preceding two Phase 2a trials $(M=8.6)$, but this difference just failed to reach significance, $t(4)=2.28$. The near group showed only a small and nonsignificant, $t(4)=1.0$, difference in number of choices to visit all sites during Phase $2 \mathrm{~b}(M=11.4)$ relative to Phase $2 \mathrm{a}(M=10.1)$. Nevertheless, in the absence of distinct food-site cues during Phase $2 b$, both groups were significantly 
Table 2

Proportion of Choices of Food Sites at Different Units of Separation in the Preferred ( + ) and Nonpreferred ( - ) Direction for the Last 10 Sessions of Phase Ia and Phase $2 a$ in Experiment 2

\begin{tabular}{|c|c|c|c|c|c|c|c|c|}
\hline \multirow[b]{2}{*}{ Subject } & \multicolumn{8}{|c|}{ Choice proportion } \\
\hline & -3 & -2 & -1 & 0 & +1 & +2 & +3 & +4 \\
\hline \multicolumn{9}{|c|}{ Phase la: Circular arrangement } \\
\hline \multicolumn{9}{|l|}{ Experienced } \\
\hline 1 & .143 & .100 & .100 & 0 & .357 & .157 & .086 & .057 \\
\hline 2 & .071 & .100 & .100 & 0 & .229 & .286 & .143 & .071 \\
\hline 3 & .028 & .086 & .043 & 0 & .543 & .286 & .014 & 0 \\
\hline 4 & .029 & 0 & .057 & 0 & .728 & .114 & .043 & .029 \\
\hline$M$ & .068 & .071 & .075 & 0 & .464 & .211 & .072 & .039 \\
\hline \multicolumn{9}{|l|}{ New } \\
\hline 5 & .014 & .014 & 0 & 0 & .729 & .157 & .057 & .029 \\
\hline 6 & .043 & .057 & .243 & 0 & .528 & .043 & .043 & .043 \\
\hline 7 & .029 & .029 & .157 & 0 & .600 & .071 & .057 & .057 \\
\hline 8 & .014 & 0 & .057 & 0 & .829 & .071 & 0 & .029 \\
\hline 9 & .014 & .143 & .228 & 0 & .386 & .129 & .043 & .057 \\
\hline 10 & .043 & 0 & .014 & 0 & .743 & .114 & .072 & .014 \\
\hline$M$ & .026 & .040 & .117 & 0 & .636 & .098 & .045 & .038 \\
\hline \multicolumn{9}{|c|}{ Phase 2a: Linear rows arrangements } \\
\hline \multicolumn{9}{|c|}{ 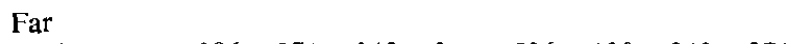 } \\
\hline 1 & .086 & .071 & .043 & 0 & .586 & .100 & .043 & .071 \\
\hline 2 & .100 & .172 & .100 & 0 & .257 & I & .100 & .100 \\
\hline 5 & 0 & .014 & .029 & 0 & .714 & .186 & .057 & 0 \\
\hline 6 & 0 & .057 & .243 & 0 & .457 & .143 & .043 & .057 \\
\hline 7 & .028 & .043 & .043 & 0 & .686 & .086 & .086 & .028 \\
\hline$M$ & .043 & .071 & .092 & 0 & .540 & .137 & .066 & .051 \\
\hline \multicolumn{9}{|l|}{ Near } \\
\hline 3 & .043 & .114 & .157 & .014 & .329 & .171 & .072 & .100 \\
\hline 4 & .114 & .115 & .157 & 0 & .357 & .043 & .157 & .057 \\
\hline 8 & .100 & .157 & .214 & 0 & .315 & .114 & .057 & .043 \\
\hline 9 & .029 & .071 & .200 & 0 & .257 & .300 & 0 & .143 \\
\hline 10 & .014 & .014 & .114 & 0 & .600 & .172 & .014 & .072 \\
\hline$M$ & .060 & .094 & .168 & .003 & .372 & .160 & .060 & .083 \\
\hline
\end{tabular}

more accurate than the $70 \%$ chance level, far group, $t(4)=$ $3.42, p<.05$ and near group, $t(4)=5.26, p<.01$, and took significantly fewer choices to visit all sites than expected by chance, far group, $t(4)=7.71, p<.01$; near group, $t(4)=$ $4.97, p<.01$. Thus, distinct food-site cues were not necessary for accurate performance, although the far group did show some disruption by removal of these food-site cues, a result indicating that they may have used these visual intramaze cues, together with spatial room cues, to achieve their high levels of accuracy during Phase $2 \mathrm{a}$.

Control trials. During control trials, the number of unbaited food sites visited in the first eight choices $(M=3.4)$ was not significantly different, $t(9)=0.51$, from the number of baited food sites $(M=3.5)$. There was also no significant difference between the number of choices made before all unbaited food sites were visited $(M=10.5)$ and the number of choices made before all baited food sites were visited $(M=$ $10.3), t(9)=0.64$. Therefore the birds did not appear able to detect the presence or absence of food in the sites before "entering" the cartons.

\section{General Discussion}

The present results provide clear evidence that in an openfield type of feeding environment, pigeons can display accurate spatial working memory without the special or extended training that they seem to require in the radial arm maze (cf. Roberts \& Van Veldhuizen, 1985). These results, together with those of Roberts and Van Veldhuizen, strongly refute the suggestion that pigeons, unlike rats, have not evolved the capacity to accurately remember the spatial location of recently visited sites (Bond et al., 1981).

Although there was a general tendency in all conditions for the pigeons to choose adjacent food sites, several lines of evidence suggested that most birds did not rely on a response strategy alone to solve the task. First, computer simulations of sampling according to the individual birds' response biases uniformly generated accuracy scores that were lower than those displayed by the birds. Second, the pigeons showed above-chance accuracy in locating unvisited food sites following forced choice to four randomly selected sites (Phase 2 of Experiment 1), a procedure that prevents the pigeon from using a response strategy to choose accurately. Third, there were large differences between birds in terms of the degree to which they displayed response bias during Experiment 2 (see Table 2 and Figures 7 and 9), and yet all the birds performed accurately. Finally, Bird 8 , which developed the strongest tendency to circle the maze in the circular arrangement (Figure 7) was nevertheless able to perform accurately in the linear arrangement in which it did not display a consistent pattern of choices (Figure 9).

In any case, it should be noted that response patterning can arise for reasons other than an inability to remember previously visited food sites (Foreman, 1985). An adjacent-sites bias would tend to minimize overall travel and therefore should be the most efficient way to forage in a free-choice setting. In this regard, it is interesting to note that the near arrangement, in which traveling distances between all sites were minimal, appeared to generate the lowest degree of response bias of the three arrangements used in Experiment 2 (see Table 2). This is consistent with the findings of Yoerg and Kamil (1982) and Foreman (1985), that the size of the maze affects the degree to which rats show consistent response patterns.

The results of the tests with visually identical food sites in Experiment 2 suggested that for the most part, the birds did not depend on food-site (i.e., intramaze) cues to perform accurately. A significant disruption in accuracy after a change from visually distinct to visually identical food sites was seen only with the far linear arrangement, and even in this condition accuracy was still well above chance level with the visually identical food sites. It should be noted, however, that because these tests did not place spatial and food-site cues in opposition, the results indicate only that food-site cues were not necessary for accurate performance; these cues may neverthe- 
BIRD 2

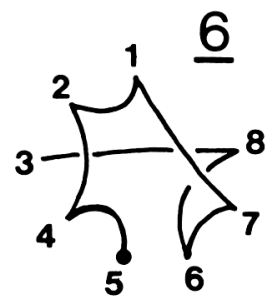

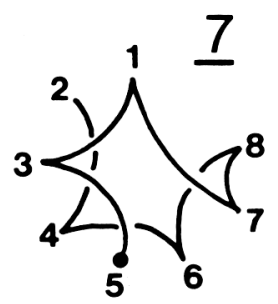

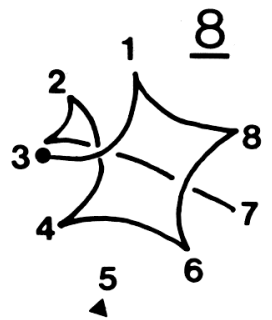

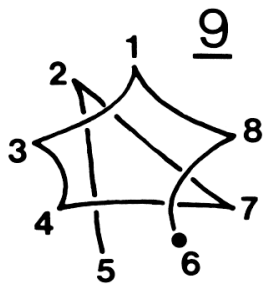

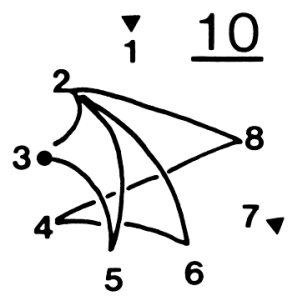

BIRD 9
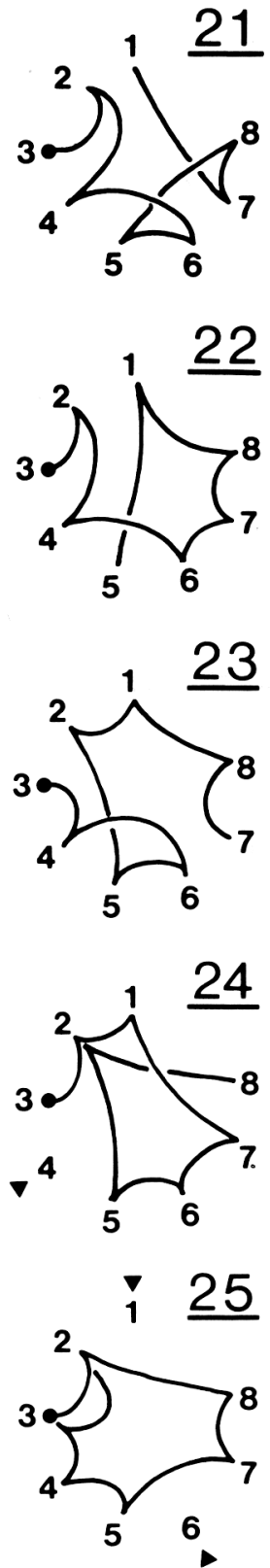

BIRD 4<smiles>[2H]C(CC)CC(C)CC(C)CC(C)C(C)CS</smiles>

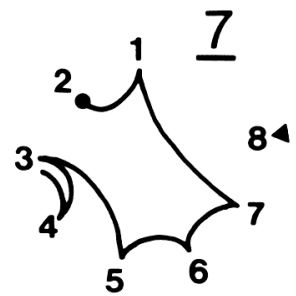<smiles>[2H][C@H]1[C@H]([2H])C[C@@H](C)[C@@H]([2H])[C@@H]1[2H]</smiles>

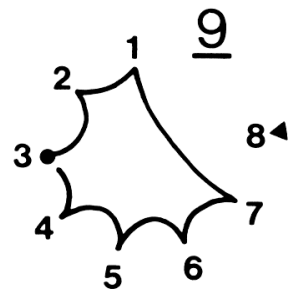

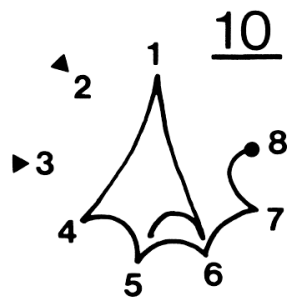

BIRD 8<smiles>[2H]C(C)CC(C)CC(C)CC(C)CC</smiles>

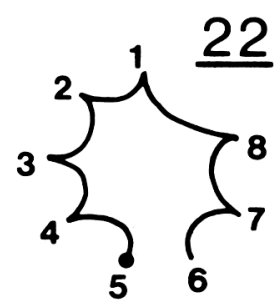<smiles>[2H]CC(C)CC([B])CC([2H])CC(C)C(C)CC</smiles>

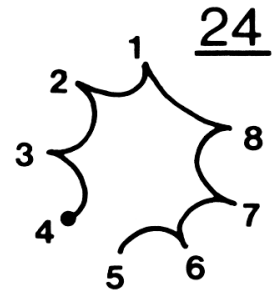

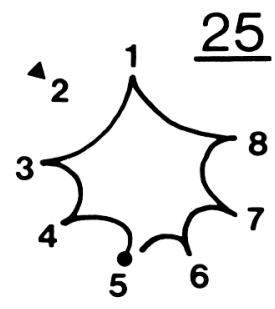

Figure 7. Choice patterns for the last five trials of Phase 1a (circular arrangement) in Experiment 2. (The dot in each tracing indicates the bird's first choice; pointers indicate sites not chosen in the first eight choices. Choice patterns are shown for birds that displayed the least tendency to "circle" [Bird 2 from the experienced group and Bird 9 from the new group] and the greatest "circling" tendency [Bird 4, experienced, and Bird 8, new].)

less have provided additional but redundant information for the birds during baseline.

Of the two test environments used, the ground-feeding version appeared to be the most suitable for studying spatial memory in pigeons, not only because it yielded higher levels of choice accuracy but also because the pigeons were much quicker to complete trials. Although the time taken to complete trials was not systematically recorded in Experiment 1, it was noted that the pigeons frequently took more than 10 min to complete a trial in the flight apparatus and even exceeded the 15-min time limit on a considerable number of days (a situation resulting in cancellation of those trials). In 
MARCIA L. SPETCH AND CHARLES A. EDWARDS
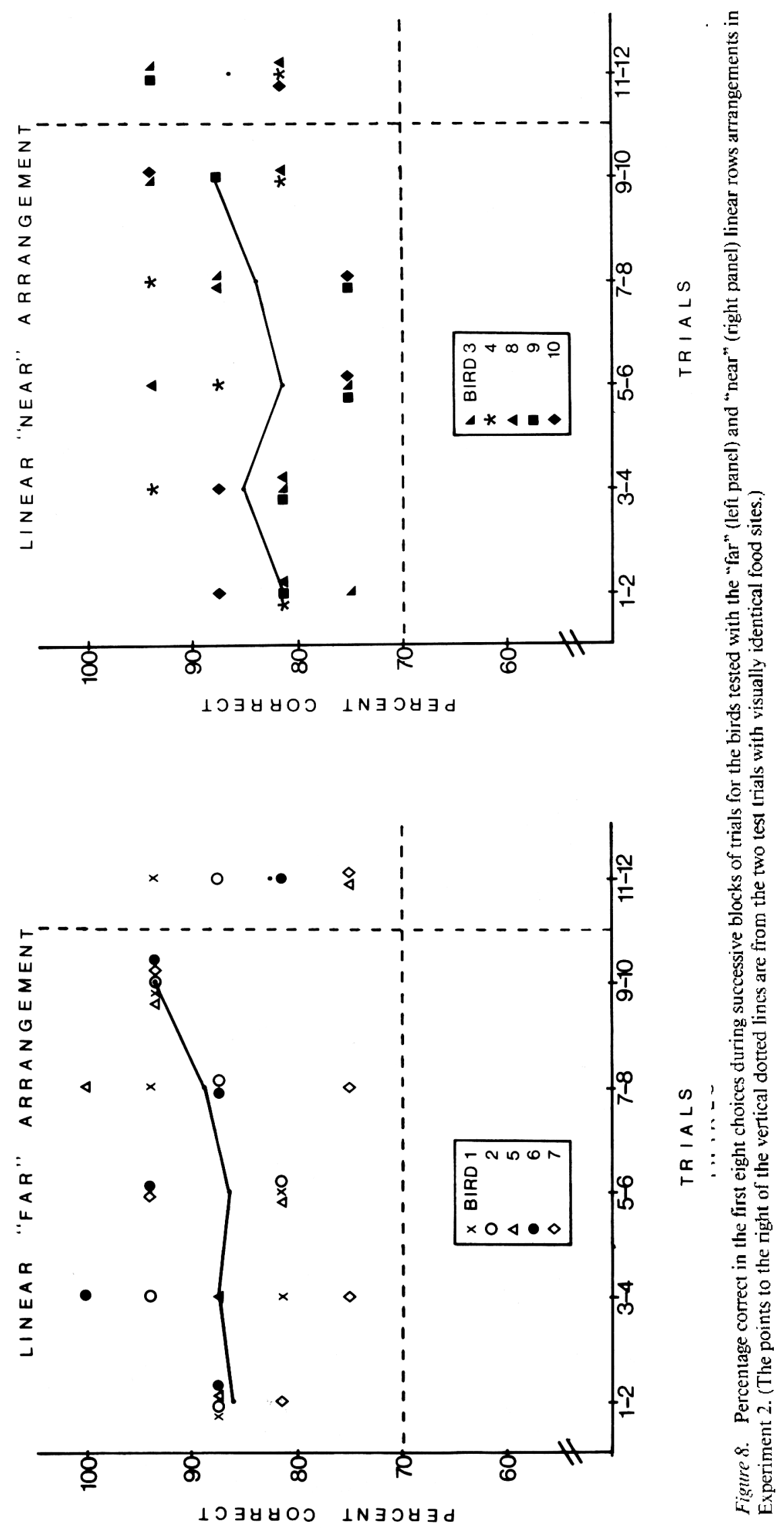
BIRD 2
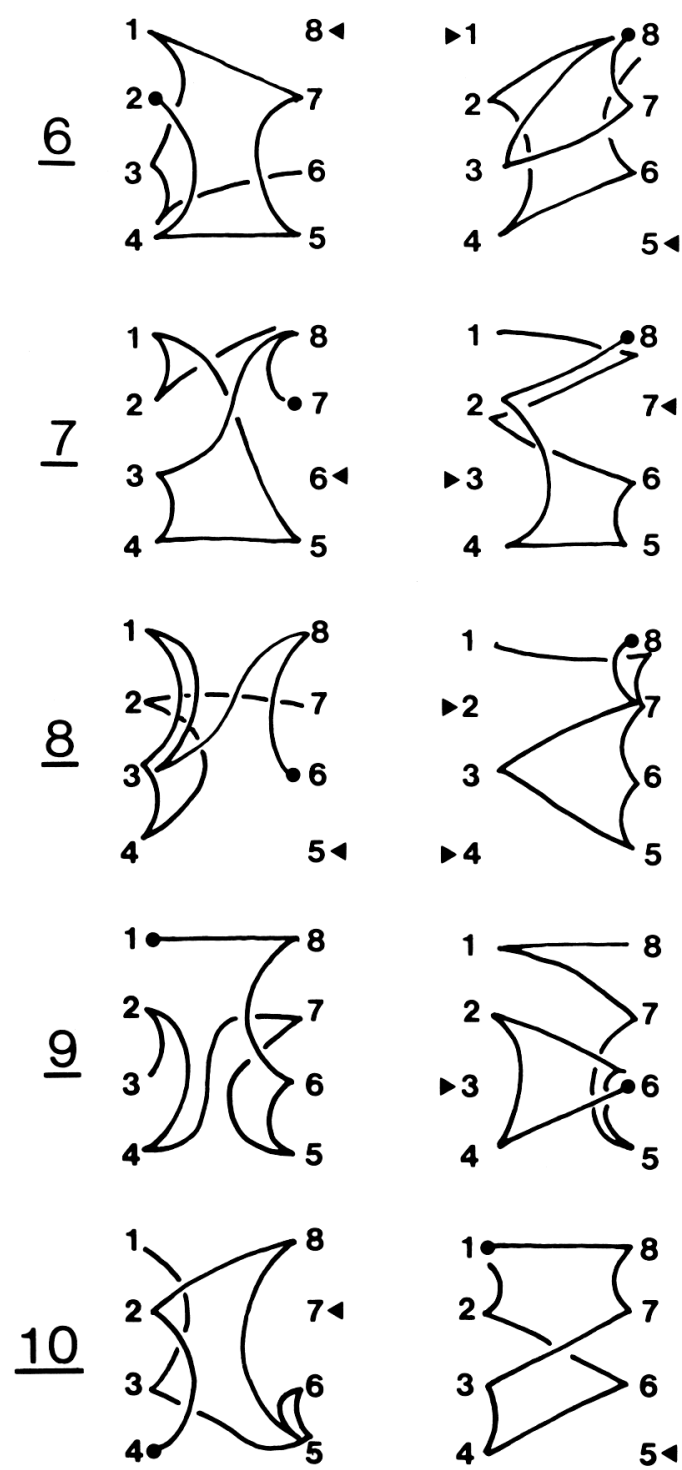

BIRD 4
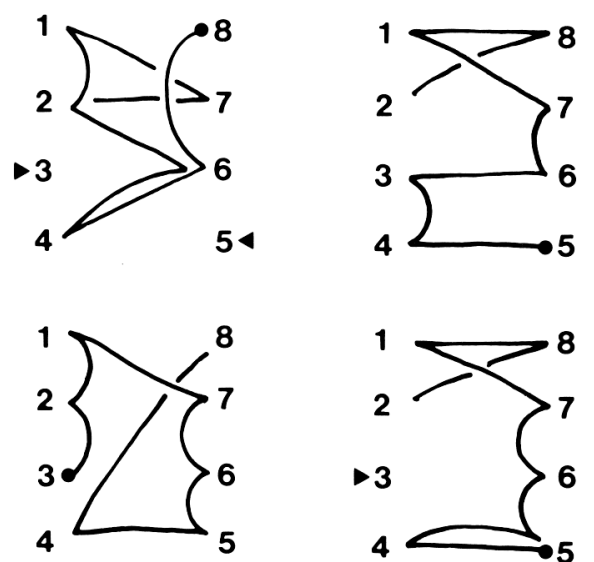

BIRD 8
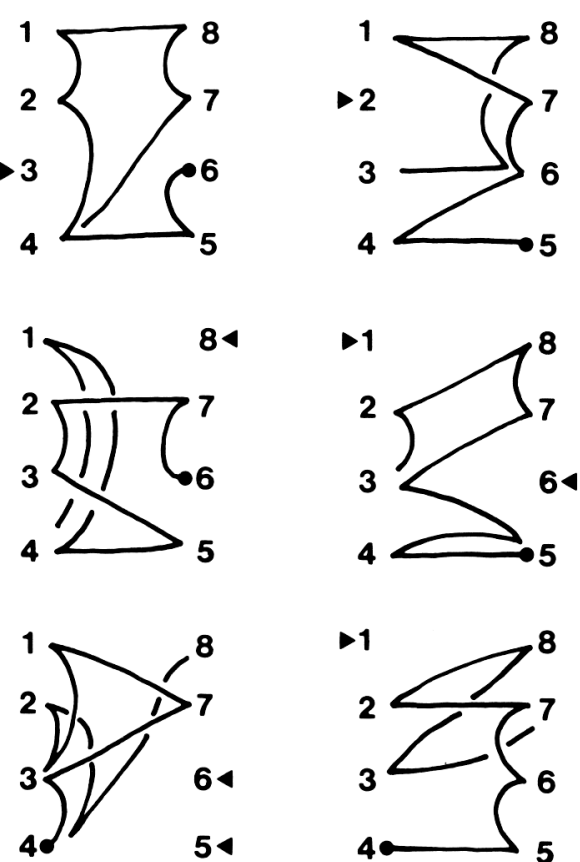

Figure 9. Choice patterns for the last five trials (Trials 6-10) of Phase 2a (linear arrangement) in Experiment 2. (Tracings are shown for birds that had previously shown the weakest and strongest tendencies to "circle" in the circular arrangement. Bird 2 was tested in the far linear arrangement; Birds 9,4 , and 8 were tested in the near arrangement.)

contrast, during the last five trials of Phase la of Experiment 2 , the average time taken to complete a trial (i.e., visit all eight sites) in the ground-feeding apparatus ranged from 1.2 min to $5.3 \mathrm{~min}$ across the 10 birds, with a mean of $2.75 \mathrm{~min}$.

One reason why pigeons might perform more readily (and perhaps more accurately) in a ground-feeding apparatus than in a flight apparatus is that eating from the ground is more natural for pigeons; in the wild, pigeons tend to eat from the ground in open areas (Goodwin, 1983) and "walk and run about quickly when feeding" (Goodwin, 1967, p. 56). In addition, Goodwin (1954) suggested that pigeons "have an innate tendency to go to the ground when hungry, for handreared young ones that have never been fed at ground level will do so if left without food" (p. 201). Although pigeons use flight to reach feeding grounds and can be taught to seek food on ledges or window sills (Goodwin, 1983), the elevated food perches used in Experiment 1 might not have been an ideal stimulus for feeding behavior. In fact, the frequent pausing behavior observed might indicate that the perches served as an elicitor of resting rather than feeding, as pigeons regularly use ledges or roofs with a wall on one side as roosting or resting places (Goodwin, 1954).

The open-room ground-feeding apparatus of Experiment 2 also offers some unique advantages for the study of spatial memory because of its flexibility. The movable ground-feeding sites allow one to easily vary a number of features, such 
Table 3

Observed and Simulated Accuracy Scores for the Last 10 Sessions of Phase Ia and Phase 2a in Experiment 2

\begin{tabular}{|c|c|c|c|c|}
\hline \multirow[b]{2}{*}{ Subject } & \multicolumn{2}{|c|}{$\begin{array}{l}\text { No. correct in first } \\
\text { eight choices }\end{array}$} & \multicolumn{2}{|c|}{$\begin{array}{l}\text { Total no. choices to } \\
\text { visit all eight sites }\end{array}$} \\
\hline & Observed & Simulated & Observed & Simulated \\
\hline \multicolumn{5}{|c|}{ Phase 1a: Circular arrangement } \\
\hline \multicolumn{5}{|c|}{ Experienced } \\
\hline 1 & 6.7 & 5.66 & 10.4 & 18.67 \\
\hline 2 & 7.2 & 5.66 & 9.7 & 18.73 \\
\hline 3 & 7.3 & 5.99 & 8.7 & 16.01 \\
\hline 4 & 6.7 & 6.37 & 12.1 & 13.81 \\
\hline \multicolumn{5}{|l|}{ New } \\
\hline 5 & 7.2 & 6.50 & 10.2 & 13.48 \\
\hline 6 & 7.7 & 5.33 & 8.4 & 20.63 \\
\hline 7 & 7.0 & 5.72 & 11.3 & 17.50 \\
\hline 8 & 7.5 & 6.68 & 9.8 & 11.85 \\
\hline 9 & 7.4 & 5.40 & 9.3 & 20.25 \\
\hline 10 & 6.9 & 6.49 & 11.5 & 13.44 \\
\hline
\end{tabular}

\begin{tabular}{rrrrr}
\multicolumn{5}{c}{ Phase 2a: Linear rows arrangement } \\
Far & \multicolumn{4}{c}{} \\
1 & 7.0 & 5.89 & 10.4 & 16.61 \\
2 & 7.1 & 5.63 & 10.8 & 19.11 \\
5 & 7.2 & 6.53 & 10.4 & 13.41 \\
6 & 7.4 & 5.44 & 9.4 & 19.61 \\
7 & 6.7 & 6.15 & 10.2 & 14.89 \\
Near & & & & \\
3 & 6.6 & 5.52 & 10.8 & 19.62 \\
4 & 7.0 & 5.57 & 11.4 & 19.35 \\
8 & 6.8 & 5.49 & 10.8 & 19.71 \\
9 & 6.4 & 5.58 & 10.8 & 19.11 \\
10 & 6.7 & 5.97 & 11.5 & 16.06 \\
\hline
\end{tabular}

as the absolute and relative spatial location of the food sites, the number of sites, and their spatial configuration. Manipulation of these variables may help us to understand the organization of spatial memory in pigeons.

\section{References}

Baird, J. (1968). Eastern Savannah sparrow. In O. L. Austin, Jr. (Ed.). Life histories of North American cardinals, grosbeaks, buntings, tow'hees, finches, sparrou's, and allies (Part 2, pp. 678-696). Washington, DC: Smithsonian Institution Press.

Balda, R. P., \& Turek, R. J. (1984). The cache-recovery system as an example of memory capabilities in Clark's nutcracker. In H. L. Roitblat. T. G. Bever. \& H. S. Terrace (Eds.), Animal cognition (pp. 513-532). Hillsdale, NJ: Erlbaum.

Bond, A. B., Cook, R. G., \& I amb, M. R. (1981). Spatial memory and performance of rats and pigeons in the radial-arm maze. Animal Learning \& Behavior, 9. 575-580.

Cowie, R. J., Krebs, J. R., \& Sherry, D. F. (1981). Food storing by marsh tits. Animal Behaviour, 29, 1252-1259.

Foreman, N. (1985). Algorithmic responding on the radial maze in rats does not always imply the absence of spatial encoding. Quarterly Journal of Experimental Psychology, 37B, 333-358.

Goodwin, D. (1954). Notes of feral pigeons. Avicultural Magazine, $60,190-213$.

Goodwin, D. (1967). Pigeons and doves of the world. London: Trustees of the British Museum (Natural History).
Goodwin, D. (1983). Behaviour. In M. Abs (Ed.), Physiology and behaviour of the pigeon (pp. 285-308). London: Academic Press.

Horner, J. (1984). The effect of maze structure upon the performance of a multiple goal task. Animal Learning \& Behavior, 12, 55-61.

Kamil, A. C. (1978). Systematic foraging by a nectar-feeding bird, the amakihi (Loxops virens). Journal of Comparative and Physiological Psychology, 92, 388-396.

Kraemer, P. J., Gilbert, M. E., \& Innis. N. K. (1983). The influence of cue type and configuration upon radial-maze performance in the rat. Animal Learning \& Behavior, H1, 373-380.

Menzel, E. W. (1973). Chimpanzee spatial memory organization. Science, 182, 943-945.

Menzel, E. W. (1978). Cognitive mapping in chimpanzees. In S. H. Hulse, H. Fowler, \& W. K. Honig (Eds.), Cognitive processes in animal behavior (pp. 375-422). Hillsdale, NJ: Erlbaum.

Moore, F. R., \& Osadchuk, T. E. (1982). Spatial memory in a passerine migrant. In F. Papi \& H. G. Wallraff (Eds.), Avian navigation (pp. 319-325). New York: Springer.

Olson, D. J., \& Maki, W. S. (1983). Characteristics of spatial memory in pigeons. Journal of Experimental Psychology: Animal Behavior Processes, 9, 266-280.

Olton, D. S. (1977). Spatial memory. Scientific American, 236(6), 82-98.

Olton, D. S. (1978). Characteristics of spatial memory. In S. H. Hulse, H. Fowler, \& W. K. Honig (Eds.), Cognitive processes in animal behavior (pp. 341-373). Hillsdale NJ: Erlbaum.

Roberts, W. A. (1984). Some issues in animal spatial memory. In $\mathrm{H}$. L. Roitblat, T. G. Bever, \& H. S. Terrace (Eds.), Animal cognition (pp. 425 443). Hillsdale, NJ: Erlbaum.

Roberts, W. A., \& Van Veldhuizen, N. (1985). Spatial memory in pigeons on the radial maze. Journal of Experimental Psychology: Animal Behavior Processes, 11, 241-260.

Roitblat, H. L., Tham, W., \& Golub, L. (1982). Performance of Betta splendens in a radial arm maze. Animal Learning \& Behavior, 10 . $108-114$.

Sherry, D. F. (1982). Food storage, memory, and marsh tits. Animal Behaviour, 30, 631-633.

Sherry. D. (1984). Food storage by black-capped chickadees: Memory for the location and contents of caches. Animal Bchaviour, 32, $451-464$.

Spetch, M. L., \& Wilkie, D. M. (1980). A program that simulates random choice in radial arm mazes and similar choice situations. Behavior Research Methods \& Instmimentation, 12, 377-378.

Squires, N., \& Fantino, E. (1971). A model for choice in simple concurrent and concurrent-chains schedules. Journal of the Experimental Analysis of Behavior, 15, 27-38.

Tomback, D. F. (1980). How nutcrackers find their seed stores. Condor, 82, 10-19.

Vander Wall, S. B. (1982). An experimental analysis of cache recovery in Clark's nutcracker. Animal Behaviour, 30, 84-94.

Wilkie, D. M., \& Slobin. P. (1983). Gerbils in space: Performance on the 17-arm radial maze. Joumal of the Experimental Analysis of Behavior, 40, 301-312.

Wilkie, D. M., \& Spetch, M. L. (1980). [Pigeons' performance in an eight-arm radial maze]. Unpublished raw data.

Wilkie, D. M., Spetch, M. L., \& Chew, L. (1981). The ring dove's short-term memory capacity for spatial information. Animal Behaviour, 29, 639-641.

Yoerg, S. L., \& Kamil, A. C. (1982). Response strategies in radial arm mazes: Running around in circles. Animal Learning \& Behavior, 10, 530-534.

Received August 8, 1985

Revision received February 26, 1986 